\title{
Optimization of ultrasound-assisted extraction of bioactive compounds from jabuticaba (Myrciaria cauliflora) fruit through a Box-Behnken experimental design
}

\author{
Gerardo FERNÁNDEZ-BARBERO ${ }^{1}$, Cristina PINEDO², Estrella ESPADA-BELLIDO ${ }^{1 *}$ (D), \\ Marta FERREIRO-GONZÁLEZ ${ }^{1}$, Ceferino CARRERA ${ }^{1,3}$, Miguel PALMA ${ }^{1}$, Carmelo GARCÍA-BARROSO ${ }^{1}$
}

\begin{abstract}
Jabuticaba is a very popular fruit in Brazil being a great source of compounds with considerable biological activities. Novel optimized ultrasound-assisted extraction (UAE) methods have been proposed for anthocyanins and total phenolic compounds from jabuticaba. A Box-Behnken experimental design (BBD) with a response surface methodology (RSM) was used to investigate the effect of six independent variables (solvent composition, solvent-to-sample ratio, ultrasound amplitude and cycle, $\mathrm{pH}$, and temperature) on the UAE. Solvent composition was found to be the most significant variable for the extraction of both anthocyanins (51\%) and total phenolic compounds (72\%). The other optimum conditions for anthocyanins were as follows: $\mathrm{pH} 7.00,39.8^{\circ} \mathrm{C}, 20: 1.5 \mathrm{~mL}: \mathrm{g}$ solvent-to-sample ratio, $34 \%$ ultrasound amplitude and cycle of 0.47 seconds. The optimum conditions for the extraction of phenolic compounds were: $\mathrm{pH} 7.00,26.0^{\circ} \mathrm{C}, 20: 1.5$ (mL:g) solvent-to-sample ratio, $68.5 \%$ ultrasound amplitude and cycle of 0.5 seconds. The extraction kinetic was also evaluated. The developed methods showed a high precision, with coefficients of variation of less than $5 \%$ for both repeatability and intermediate precision (within-lab reproducibility). The applicability of the new methods was successfully evaluated on several fruits and jams from jabuticaba.
\end{abstract}

Keywords: anthocyanins; Box-Behnken experimental design; jabuticaba; optimization; phenolic compounds, ultrasound-assisted extraction.

Practical Application: Ultrasound-assisted extraction (UAE) is a faster, easier and greener alternative to conventional extraction methods. In this paper, the optimization of UAE of bioactive compounds (anthocyanins and total phenolic compounds) from jabuticaba using a Box-Behnken design with a response surface methodology (RSM) has been proposed. The effect of solvent composition, solvent-to-sample ratio, ultrasound amplitude and cycle, $\mathrm{pH}$, and temperature was evaluated. The methods were successfully applied to several fruits and jams from jabuticaba. The findings are of interest in the field of food analysis.

\section{Introduction}

The fruit of the jabuticaba tree (Myrciaria cauliflora) (Mitra, 2010) has the special characteristic that it is borne directly on the main trunk and branches of the tree. Jabuticaba is very well known in South America, especially in Brazil (Nascimento et al., 2013). This fruit is produced twice a year and the average yield of a mature tree can be over 1000 pounds of fruit (Costa et al., 2016; Teixeira et al., 2011). This fruit is dark and has a spherical shape with a small size $(3.0-4.0 \mathrm{~cm})$ and it is highly appreciated due to its relevant nutritional properties (Silva et al., 2008; Wu et al., 2013). The high content of carbohydrates, proteins, vitamins, minerals, and fibers have made jabuticaba a daily food in the diet of native people for many years (Borges et al., 2014). There are several references concerning the chemical composition of Myrciaria cauliflora and the relevant content of bioactive compounds has been highlighted, including phenolics in general and anthocyanins in particular, which are characterized by their antioxidant, anticancer, and beneficial properties against chronic diseases (Batista et al., 2014; Dessimoni-Pinto et al., 2011; Lenquiste et al., 2015; Nascimento et al., 2013). This fruit is

appreciated for both fresh consumption and jam manufacturing (Alves et al., 2016). In some recent studies it has even been shown that the addition of $1-2 \%$ of freeze-dried jabuticaba peel to the diet improves health (de Sá et al., 2014). Among the anthocyanins that are naturally present in this fruit, six are more abundant than the others: pelargonidin, delphinidin, cyanidin, petunidin, peonidin and malvidin (Reynertson et al., 2006). These anthocyanins differ in the number and position of their hydroxyl and methoxyl groups. The main anthocyanins that have been extracted and identified in the fruit of jabuticaba are cyanidin-3-O-glucoside and delphinidin-3-O-glucoside (Figure 1) (Alves et al., 2013; Reynertson et al., 2006) in addition to the other predominant phenolic compounds such as jaboticabin, ellagic acid, and gallic acid (Abe et al., 2012; Alezandro et al., 2013). The extraction procedure for anthocyanins and other phenolic compounds from jabuticaba is undoubtedly of great importance in food industry. However, in spite of the appealing properties of this fruit, only a few papers have been published on the extraction of these components. On the one hand,

Received 14 May, 2018

Accepted 15 Oct., 2018

${ }^{1}$ Department of Analytical Chemistry, Faculty of Sciences, University of Cadiz, Agrifood Campus of International Excellence, Puerto Real, Cádiz, Spain

${ }^{2}$ Department of Organic Chemistry, Faculty of Sciences, University of Cadiz, Puerto Real, Cádiz, Spain

${ }^{3}$ Instituto de Investigación Vitivinícola y Agroalimentario (IVAGRO), Agrifood Campus of International Excellence (ceiA3), University of Cadiz, Puerto Real, Cádiz, Spain

*Corresponding author: estrella.espada@uca.es 


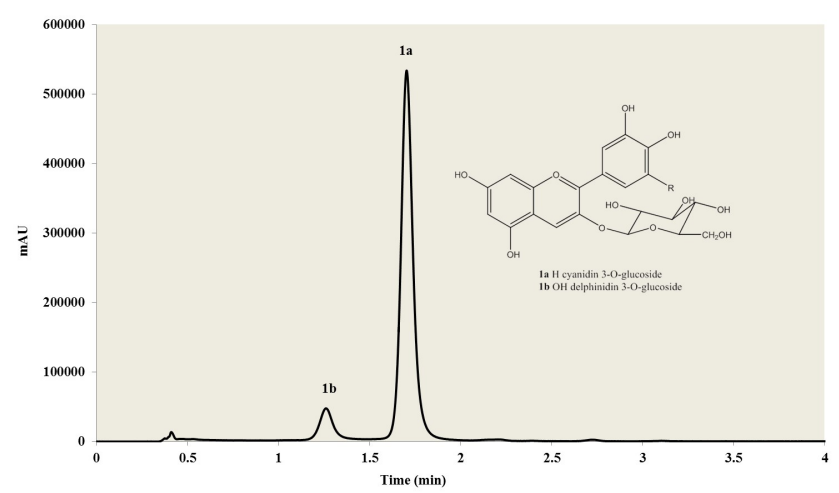

Figure 1. UHPLC-UV-vis chromatogram of the main anthocyanins identified in the UAE extracts of the jabuticaba fruit. Peak assignment: 1a) cyanidin-3-O-glucoside and $1 \mathrm{~b}$ ) delphinidin-3-O-glucoside.

Santos et al. developed a combined extraction process involving ultrasound treatment and agitated solvent extraction from an engineering point of view (Santos et al., 2010). On the other hand, Rodrigues et al. optimized an ultrasound assisted extraction method of phenolics and anthocyanins from jabuticaba peels (Rodrigues et al., 2015). The effect of only solvent, $\mathrm{pH}$ and extraction time was evaluated. There is therefore a need to develop efficient extraction procedures for this fruit. An efficient extraction should maximize metabolite recovery with minimal degradation to provide an extract with high antioxidant activity using environmentally friendly technologies and low-cost raw materials. The aim of the work described here was to optimize ultrasound-assisted extraction methods (UAE) to extract antioxidant compounds (anthocyanins and other phenolic compounds) from jabuticaba. UAE is more economical and is easier to operate than other novel extraction techniques such as pressurized liquid extraction (PLE) and microwave-assisted extraction (MAE) (Paula et al., 2016; Wang \& Weller, 2006). The UAE technique is recognized as being an extraction method for a wide variety of natural compounds including phenolic compounds (Díaz-de-Cerio et al., 2017; Dranca \& Oroian, 2016; Espada-Bellido et al., 2017; He et al., 2016; Lazar et al., 2016; Rodrigues et al., 2015; Sharmila et al., 2016). The UAE method is a very interesting technique for the extraction of natural compounds from fruits and plants as it enhances mass transport by disrupting the plant cell walls. Consequently, ultrasonic power is considered to be one of the factors that leads to the enhancement of the extraction (Barizão et al., 2015; Wang \& Weller, 2006). Several factors can have an impact on the efficiency of ultrasound, such as solvent composition, solvent-to-sample ratio, ultrasound amplitude and cycle, $\mathrm{pH}$, and temperature. In this paper, the effects of the six selected variables on the extraction efficiency of the compounds of interest have been analyzed through a Box-Behnken experimental design (BBD) with a response surface methodology (RSM), which consists of mathematical techniques to maximize the analytical response (Ding et al., 2016; Filip et al., 2017). Thus, the aim of the study reported here was to optimize two novel ultrasound-assisted extraction (UAE) methods for individual anthocyanins and total phenolic compounds in jabuticaba fruit. Once the extraction methods had been optimized, they were validated and applied to the extraction and analysis of different samples of jabuticaba fruits and its derived products such as jams. The results can be of interest in the field of food analysis, and in particular for the analysis of phenolic compounds in jabuticaba fruit and its derived products.

\section{Materials and methods}

\subsection{Chemicals and solvents}

Methanol (MeOH) (Fisher Scientific, Loughborough, UK) and formic acid (Scharlau, Barcelona, Spain) used for the chromatographic separation were HPLC grade. Hydrochloric acid and sodium hydroxide (Panreac, Barcelona, Spain) used to regulate the $\mathrm{pH}$ of the extraction solvent were analytical grade. Ultra pure water was obtained from a Milli-Q water purification system from Millipore (Bedford, MA, USA). For the determination of total phenolic compounds, Folin-Ciocalteu reagent (Merck KGaA, Darmstadt, Germany) and anhydrous sodium carbonate (Panreac, Barcelona, Spain) were used. Cyanidin chloride, a commercially available standard for anthocyanins, and gallic acid for total phenolic compounds, were obtained from Sigma-Aldrich Chemical Co. (St. Louis, MO, USA).

\subsection{Jabuticaba samples}

In order to proceed with the development of the extraction methods, fresh jabuticaba fruit (Myrciaria cauliflora) was acquired from a local market from São Paulo (Brazil). The seeds of the fruit were removed and the rest of the fruit (peel and pulp) were conveniently triturated and homogenized in a Thermomix (Vorwerk, Madrid, Spain) until obtaining a puree. The triturated samples were immediately frozen at $-20^{\circ} \mathrm{C}$ and stored prior to analysis. Jabuticaba jams were also purchased from Brazilian markets located in Campinas, SP, Brazil and stored at $4{ }^{\circ} \mathrm{C}$. The jams were crushed and homogenized in a conventional grinder prior to analysis.

\subsection{Extraction procedure}

UAE was carried out using at 200 Watts and $24 \mathrm{kHz}$ on a UP200S ultrasonic system (Ultraschallprozessor Dr. Hielscher Ultrasonics GmbH, Berlin, Germany) that allows the cycle and ultrasound amplitude to be selected. A $7 \mathrm{~mm}$ diameter probe was used for the experiments. This compact ultrasonic system is designed to be mounted on a stand and is equipped with a water bath coupled to a temperature controller (Frigiterm-10 J.P. Selecta, Barcelona, Spain) to maintain the desired extraction temperature. A jabuticaba sample (1.5 g) was accurately weighed and then placed in a Falcon $50 \mathrm{~mL}$ tube and, depending on the experimental design, a different volume and solvent composition was added to the tube and the extraction was performed under controlled UAE conditions. The ultrasound probe was introduced into the Falcon up to $0.5 \mathrm{~cm}$ above the bottom of the tube, without touching their walls. After extraction, the samples were cooled to room temperature and filtered by gravity. The Falcon tube was washed twice with the same solvent and the filtered extract was placed in a $25 \mathrm{~mL}$ volumetric flask, and adjusted to a final volume of $25 \mathrm{~mL}$ with methanol. The extracts were filtered through a $0.22 \mu \mathrm{m}$ nylon syringe filter (Filter-Lab, Filtros Anoia, S.A., Sant Pere de Riudebitlles, Barcelona, Spain) prior to chromatographic analysis. The extracts were kept at $-20^{\circ} \mathrm{C}$ 
prior to analysis. The extraction time used for the development of the optimization was 10 minutes.

\subsection{Identification of anthocyanins by UHPLC-Q-ToF-MS}

Ultra high-perfomance liquid chromatography (UHPLC) coupled to quadrupole-time-of-flight mass spectrometry (Q-ToF-MS) (Synapt G2, Waters Corp., Milford, MA, USA) was used to identify anthocyanins. The injection volume was set to $3 \mu \mathrm{L}$ and the chromatographic separation was performed on a reverse-phase C18 analytical column (Acquity UPLC BEH C18, Waters) of $2.1 \mathrm{~mm} \times 100 \mathrm{~mm}$ and $1.7 \mu \mathrm{m}$ particle size. The gradient elution program was an acidified aqueous solution ( $2 \%$ formic acid) as mobile phase A and methanol as mobile phase $\mathrm{B}$, both at a flow rate of $0.4 \mathrm{~mL} \mathrm{~min}^{-1}$. The gradient applied was: $0 \mathrm{~min}, 15 \% \mathrm{~B} ; 3.30 \mathrm{~min}, 20 \% \mathrm{~B} ; 3.86 \mathrm{~min}, 30 \% \mathrm{~B}$; $5.05 \mathrm{~min}, 40 \% \mathrm{~B} ; 5.35 \mathrm{~min}, 55 \% \mathrm{~B} ; 5.64 \mathrm{~min}, 60 \% \mathrm{~B}, 5.95 \mathrm{~min}$, $95 \% \mathrm{~B} ; 7.50 \mathrm{~min}, 95 \% \mathrm{~B}$. Total run time was 12 minutes, including 4 minutes for re-equilibration. The determination of the extracted anthocyanins was carried out using an electrospray source operating in positive ionization mode under the following conditions: desolvation gas flow $=700 \mathrm{~L} \mathrm{~h}^{-1}$, desolvation temperature $=500{ }^{\circ} \mathrm{C}$, cone gas flow $=10 \mathrm{~L} \mathrm{~h}^{-1}$, source temperature $=150^{\circ} \mathrm{C}$, capillary voltage $=700 \mathrm{~V}$, cone voltage $=30 \mathrm{~V}$ and trap collision energy $=20 \mathrm{eV}$. Full-scan mode was used $(m / z=100-1000)$. Masslynx software (version 4.1) was used for the acquisition and treatment of data. The anthocyanins identified in the extracts of jabuticaba were cyanidin-3-O-glucoside and delphinidin-3-O-glucoside. The molecular ions $\left[\mathrm{M}^{+}\right]$for these anthocyanins showed the following $\mathrm{m} / \mathrm{z}$ ratios: cyanidin-3-O-glucoside, 449; delphinidin-3-O-glucoside, 465.

\subsection{Separation and determination of anthocyanins by UHPLC-UV-vis}

The separation and quantitation of anthocyanins were performed on an Elite UHPLC LaChrom Ultra System (VWR Hitachi, Tokyo, Japan) consisting of an L-2200U autosampler, an L2300 column oven, two L-2160U pumps and an L-2420U UV-vis detector. The column oven was adjusted to $50{ }^{\circ} \mathrm{C}$ for the chromatographic separation. The UV-vis detector was set at $520 \mathrm{~nm}$ for the analysis. The injection volume was set to $15 \mu \mathrm{L}$ and anthocyanins were analyzed on a Halo ${ }^{\mathrm{TM}} \mathrm{C} 18$ Hitachi LaChrom column $(100 \times 3 \mathrm{~mm}$ I.D., particle size $2.7 \mu \mathrm{m})$. A gradient method, using acidified water ( $5 \%$ formic acid, solvent $A$ ) and methanol (solvent B), working at a flow rate of $1.0 \mathrm{~mL} \mathrm{~min}{ }^{-1}$, was employed for the chromatographic separation. The gradient employed was as follows: $0 \mathrm{~min}, 15 \% \mathrm{~B}$; $1.50 \mathrm{~min}, 20 \% \mathrm{~B}$; $3.30 \mathrm{~min}, 30 \% \mathrm{~B} ; 4.80 \mathrm{~min}, 40 \% \mathrm{~B} ; 5.50 \mathrm{~min}, 55 \% \mathrm{~B} ; 6.00 \mathrm{~min}$, $100 \% \mathrm{~B}$. The retention times for the detected anthocyanins were 1.24 minutes for delphinidin-3-O-glucoside and 1.71 minutes for cyanidin-3-O-glucoside, respectively. The percentages of anthocyanins in the jabuticaba sample were as follows: cyanidin-3-O-glucoside (90.42\%) and delphinidin-3-O-glucoside (9.58\%). The values are the mean of two injections.

The linearity, limit of detection (LOD), limit of quantitation (LOQ) of the chromatographic method were evaluated according to the recommendations of EuraChem guide (Magnussonm \& Örnemark, 2014). All analyses were carried out in duplicate. A calibration curve for cyanidin chloride, the commercially standard used for anthocyanins, was constructed. Assuming that the different anthocyanins have similar absorbance, cyanidin-3-O-glucoside and delphinidin-3-O-glucoside were quantified from the calibration curve of cyanidin chloride, based on the structural similarities and taking into account their molecular weights. The results were expressed as micrograms of cyanidin chloride equivalents per $\mathrm{g}$ of fresh weight (Table 1). The detection and quantitation limits were calculated as the analyte concentration corresponding to the standard deviation of the signal of the blank values $(n=10)$ plus $3 \mathrm{x}$ and $10 \mathrm{x}$ times, respectively, divided by the slope of the linear regression.

\subsection{Total phenolic content determination}

The total phenolic content of the extracts obtained from jabuticaba was estimated through the modified spectrophotometric Folin-Ciocalteu method (Singleton et al., 1999; Singleton \& Rossi, 1965) for vegetable extracts. The extracts were filtered through a $0.45 \mu \mathrm{m}$ nylon syringe filter (Filter-Lab, Filtros Anoia, S.A., Sant Pere de Riudebitlles, Barcelona, Spain) prior to spectrophotometric analysis. The reaction was performed by transferring $0.25 \mathrm{~mL}$ of standard solution or extract samples into a $25 \mathrm{~mL}$ volumetric flask. Next, $12.5 \mathrm{~mL}$ of distilled water, $1.25 \mathrm{~mL}$ of Folin-Ciocalteu reagent and $5 \mathrm{~mL}$ of aqueous sodium carbonate solution $20 \%$ (w/v) were added and the solution was made up to the mark with water. The solution was manually stirred for 30 seconds and kept at room temperature for 30 minutes. The absorbance of the solution was measured at $750 \mathrm{~nm}$ on a UV-vis spectrophotometer V-530 (JASCO, Madrid, Spain) with a quartz cuvette of $10 \mathrm{~mm}$ path length.

The linearity, limit of detection (LOD), limit of quantitation (LOQ) of the colorimetric method were also evaluated according

Table 1. Analytical characteristics for the determination of total phenolic compounds (TPC) and total anthocyanins (TA).

\begin{tabular}{|c|c|c|c|c|c|c|}
\hline & \multirow{2}{*}{ Compound } & Linear range & \multirow{2}{*}{ Linear equation } & \multirow{2}{*}{$\mathrm{R}^{2}$} & \multirow{2}{*}{$\frac{\mathrm{LOD}}{\left(\mathrm{mg} \mathrm{L}^{-1}\right)}$} & \multirow{2}{*}{$\frac{\text { LOQ }}{\left(\mathrm{mg} \mathrm{L}^{-1}\right)}$} \\
\hline & & $\left(\mathrm{mg} \mathrm{L}^{-1}\right)$ & & & & \\
\hline \multirow[t]{2}{*}{ TA } & Cyanidin chloride & $0.042-35$ & $y=242789.16 x-17765.22$ & 0.9999 & 0.172 & 0.573 \\
\hline & Cyanidin-3-O-glucoside & & $y=174354.87 x-17765.22$ & 0.9999 & 0.240 & 0.780 \\
\hline
\end{tabular}


to the recommendations of EuraChem guide (Magnussonm \& Örnemark, 2014). All analyses were carried out in duplicate. Regarding the calibration curve for total phenolics, the commercially standard used was gallic acid. Total phenolic compounds were expressed as micrograms of gallic acid equivalents per gram of fresh weight (Table 1). The detection and quantitation limits were calculated as explained in section 2.5 .

\subsection{Experimental design and optimization}

In the present study, a three level Box-Behnken experimental design with a response surface methodology (Baş \& Boyac1, 2007; Grosso et al., 2014; Sharmila et al., 2016) was employed to optimize the UAE extraction conditions. The total amount of extracted anthocyanins and the total amount of phenolic compounds were considered as the response variables. In this experimental design, six independent variables at three different levels, i.e., (-1) low, (0) medium and $(+1)$ high, were studied. The six experimental variables were: solvent composition $\left(\mathrm{X}_{1} ; 25-50-75 \%\right.$ methanol in water $)$, temperature $\left(\mathrm{X}_{2} ; 10-40-70{ }^{\circ} \mathrm{C}\right)$, ultrasound amplitude $\left(\mathrm{X}_{3} ; 30-50-70 \%\right)$, cycle $\left(\mathrm{X}_{4} ; 2-4.5-7 \mathrm{~s}\right)$, $\mathrm{pH}\left(\mathrm{X}_{5} ; 3-5-7\right)$ and solvent-to-sample ratio $\left(\mathrm{X}_{6} ; 10: 1.5-15: 1.5\right.$ 20:1.5 mL:g). These specific ranges of values were selected according to the existing prior knowledge on the extraction of phenolic compounds and anthocyanins (Franquin-Trinquier et al,. 2014; Liazid et al., 2010). An experimental design matrix with 54 trials was performed in duplicate with six repetitions of the center point. Both responses obtained from the different extractions were entered into second-order polynomial equations to correlate them with the independent variables (Equation 1):

$Y=b_{0}+\sum_{i=1}^{k} b_{i} X_{i}+\sum_{i=1}^{k} b_{i i} X_{i i}^{2}+\sum_{i=1}^{k-1} \sum_{i=1}^{k} b_{i j} X_{i} X_{j}$
$Y$ is the predicted response, $b_{0}$ is the population value of the average of all the response values of the design, $X_{i}$ and $X_{j}$ are the population parameters that affect the response $Y, b_{i}, b_{i i}^{j}$ and $b_{i j}$ are called estimators of the population parameters $X_{i}$ and $X_{j}^{i j}$; $b_{i}(i=1,2, \ldots, 6)$ is the linear coefficient, $b_{i i}(i=1,2, \ldots, 6)$ is the quadratic coefficient, and $b_{i j}(i=1,2, \ldots, 6 ; \mathrm{j}=1,2, \ldots, 6)$ is the cross-product coefficient. The responses obtained from all the extractions were studied using Design Expert software 11 (Trial Version, Stat- Ease Inc., Minneapolis, MN, USA). This software was used to estimate the effects of the variables on the final response, the analysis of variance (ANOVA), the second order mathematical model, and the optimum levels of the significant variables.

\section{Results and discussion}

A Box-Behnken experimental design (BBD) with the response surface methodology (RSM) was used to evaluate the influence on the extraction yield of six factors related to UAE conditions for anthocyanins and total phenolic compounds from jabuticaba fruit. Extraction time was fixed initially at 10 minutes and the amount of jabuticaba fruit (without seeds) employed was approximately $1.5 \mathrm{~g}$. All of the runs were performed in duplicate. The experiments with the coded values of the variables are shown in Table 2 along with the experimental and estimated values for both responses. Analysis of variance (ANOVA) was performed to evaluate the significance of the variables and their interactions on the response (Tables 3 and 4 ). The extraction of both sets of bioactive compounds from jabuticaba was correlated with experimental conditions by a second-order polynomial equation, which can be useful to predict the response variables. Estimated coefficients of the linear, quadratic and interaction factors of the polynomial equations and their significance ( $p$-values) were evaluated.

Table 2. Box-Behnken design (BBD) with coded variables and experimental and predicted data for the responses $(n=2)$.

\begin{tabular}{|c|c|c|c|c|c|c|c|c|c|c|}
\hline \multirow{4}{*}{ Run } & \multicolumn{6}{|c|}{ Extraction conditions } & \multicolumn{4}{|c|}{ Experimental and estimated results } \\
\hline & \multirow{3}{*}{$\mathrm{X}_{1}$} & \multirow{3}{*}{$\mathrm{X}_{2}$} & \multirow{3}{*}{$\mathrm{X}_{3}$} & \multirow{3}{*}{$\mathrm{X}_{4}$} & \multirow{3}{*}{$\mathrm{X}_{5}$} & \multirow{3}{*}{$\mathrm{X}_{6}$} & \multirow{2}{*}{\multicolumn{2}{|c|}{$\begin{array}{c}\text { Total Anthocyanins } \\
\left(\mu \mathrm{g} \mathrm{g}^{-1}\right)\end{array}$}} & \multirow{2}{*}{\multicolumn{2}{|c|}{$\begin{array}{c}\text { Total Phenolics } \\
\left(\mu \mathrm{g} \mathrm{g}^{-1}\right)\end{array}$}} \\
\hline & & & & & & & & & & \\
\hline & & & & & & & Experimental & Estimated & Experimental & Estimated \\
\hline 1 & 0 & 0 & -1 & 0 & -1 & -1 & 474.93 & 475.26 & 3404.33 & 3311.45 \\
\hline 2 & 0 & 0 & 1 & 0 & -1 & -1 & 472.76 & 493.99 & 3869.33 & 3330.80 \\
\hline 3 & 0 & 0 & -1 & 0 & 1 & -1 & 494.43 & 505.51 & 2431.94 & 2556.24 \\
\hline 4 & 0 & 0 & 1 & 0 & 1 & -1 & 504.12 & 455.16 & 2978.29 & 2725.38 \\
\hline 5 & 0 & 0 & -1 & 0 & -1 & 1 & 449.18 & 497.81 & 2800.96 & 2915.15 \\
\hline 6 & 0 & 0 & 1 & 0 & -1 & 1 & 540.51 & 529.77 & 3022.60 & 3037.01 \\
\hline 7 & 0 & 0 & -1 & 0 & 1 & 1 & 562.71 & 541.14 & 3200.73 & 3600.55 \\
\hline 8 & 0 & 0 & 1 & 0 & 1 & 1 & 504.02 & 504.02 & 3640.62 & 3872.21 \\
\hline 9 & 0 & -1 & 0 & -1 & -1 & 0 & 450.50 & 387.97 & 2345.79 & 2305.18 \\
\hline 10 & 0 & 1 & 0 & -1 & -1 & 0 & 242.30 & 309.72 & 1367.81 & 2146.15 \\
\hline 11 & 0 & -1 & 0 & 1 & -1 & 0 & 465.33 & 378.72 & 2536.77 & 2342.89 \\
\hline 12 & 0 & 1 & 0 & 1 & -1 & 0 & 228.97 & 290.26 & 1543.30 & 1869.84 \\
\hline 13 & 0 & -1 & 0 & -1 & 1 & 0 & 499.61 & 399.96 & 2917.60 & 2266.05 \\
\hline 14 & 0 & 1 & 0 & -1 & 1 & 0 & 212.73 & 337.70 & 1723.84 & 2242.74 \\
\hline 15 & 0 & -1 & 0 & 1 & 1 & 0 & 461.02 & 355.23 & 3429.64 & 2326.29 \\
\hline 16 & 0 & 1 & 0 & 1 & 1 & 0 & 181.86 & 282.77 & 1623.33 & 1988.96 \\
\hline 17 & -1 & 0 & -1 & -1 & 0 & 0 & 226.39 & 229.05 & 1962.63 & 1083.92 \\
\hline
\end{tabular}


Table 2. Continued...

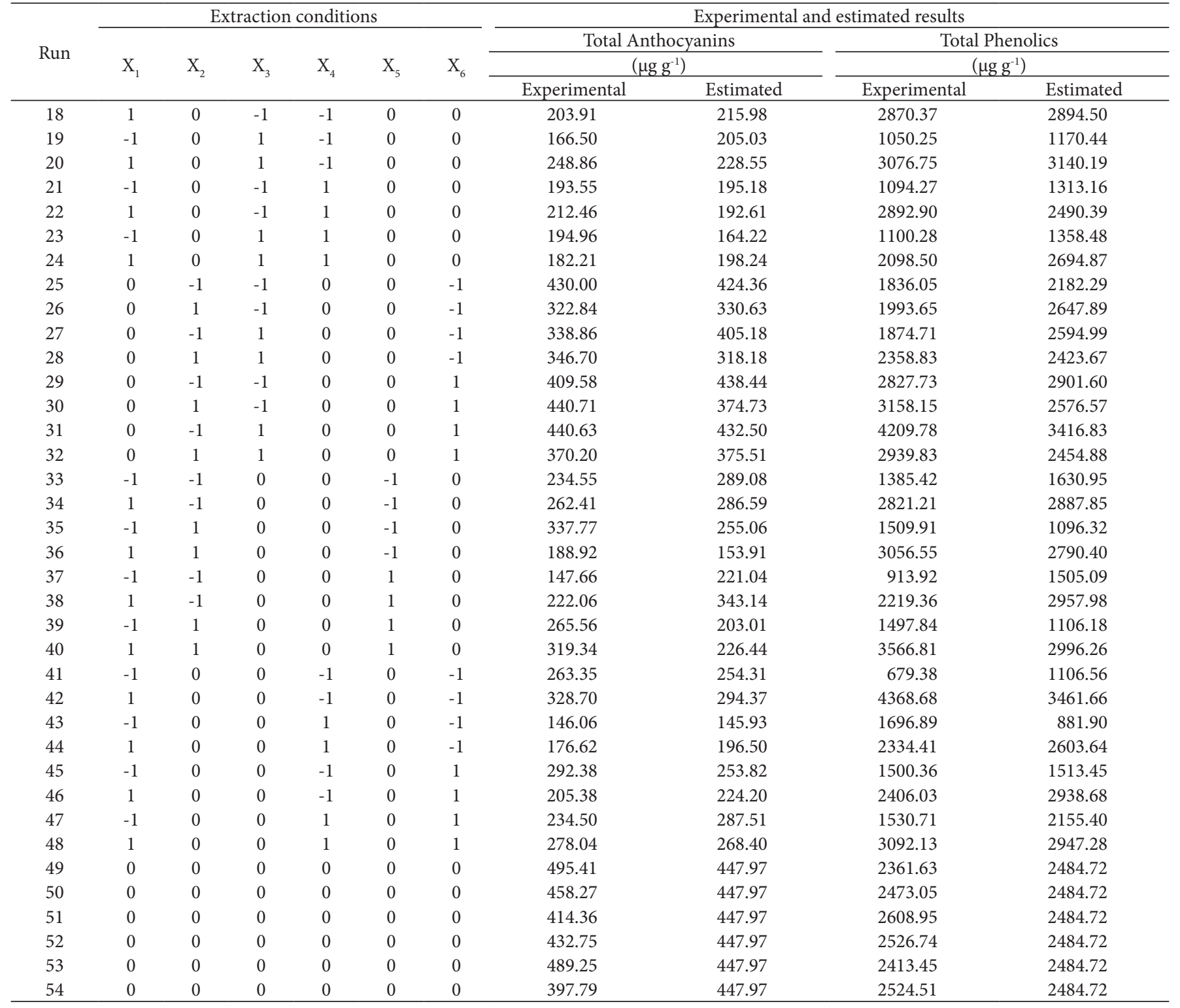

Table 3. Analysis of variance (ANOVA) of the quadratic model adjusted to the extraction of total anthocyanins.

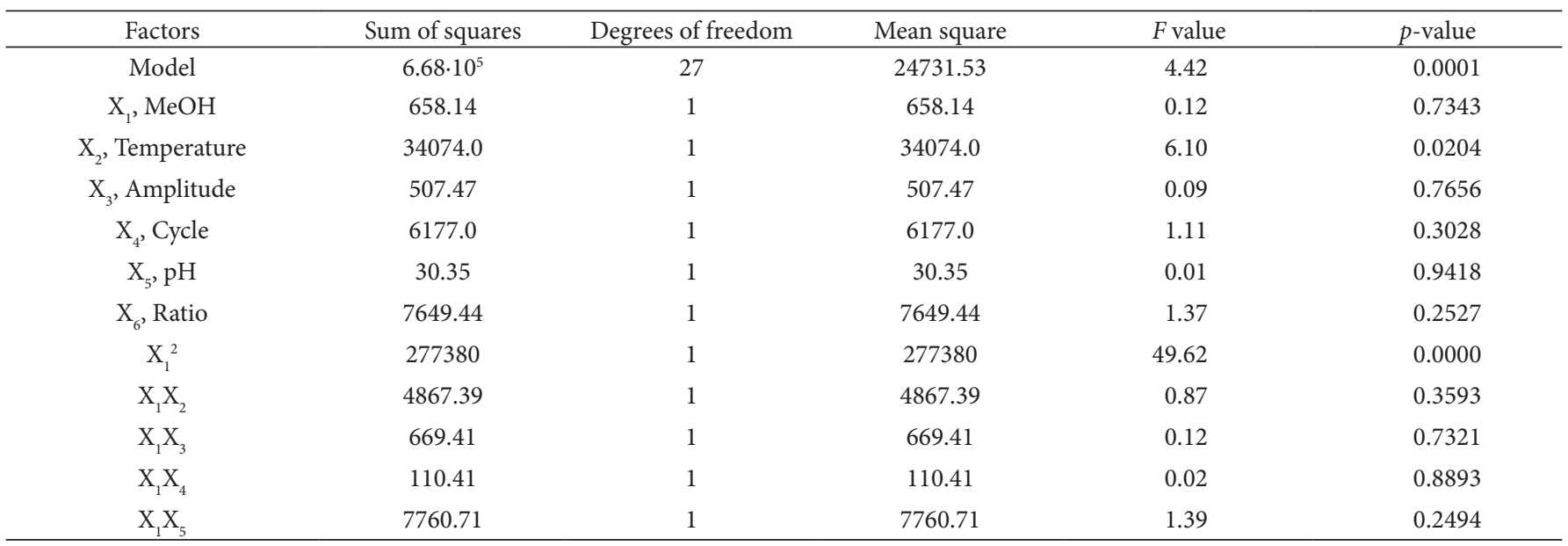


Table 3. Continued...

\begin{tabular}{|c|c|c|c|c|c|}
\hline Factors & Sum of squares & Degrees of freedom & Mean square & $F$ value & $p$-value \\
\hline $\mathrm{X}_{1} \mathrm{X}_{6}$ & 2428.0 & 1 & 2428.0 & 0.43 & 0.5157 \\
\hline $\mathrm{X}_{2}^{2}$ & 57366.4 & 1 & 57366.4 & 10.26 & 0.0036 \\
\hline $\mathrm{X}_{2} \mathrm{X}_{4}$ & 52.22 & 1 & 52.22 & 0.01 & 0.9237 \\
\hline $\mathrm{X}_{2} \mathrm{X}_{5}$ & 255.76 & 1 & 255.76 & 0.05 & 0.8323 \\
\hline $\mathrm{X}_{2} \mathrm{X}_{6}$ & 450.3 & 1 & 450.3 & 0.08 & 0.7788 \\
\hline $\mathrm{X}_{3} \mathrm{X}_{4}$ & 24.15 & 1 & 24.15 & 0.00 & 0.9481 \\
\hline $\mathrm{X}_{3} \mathrm{X}_{5}$ & 2386.02 & 1 & 2386.02 & 0.43 & 0.5193 \\
\hline $\mathrm{X}_{3} \mathrm{X}_{6}$ & 175.17 & 1 & 175.17 & 0.03 & 0.8609 \\
\hline $\mathrm{X}_{4}^{2}$ & 48561.9 & 1 & 48561.9 & 8.69 & 0.0067 \\
\hline $\mathrm{X}_{6}^{2}$ & 6733.83 & 1 & 6733.83 & 1.20 & 0.2825 \\
\hline Residual & $1.45 \cdot 10^{5}$ & 26 & 5589.90 & & \\
\hline Lack of fit & $1.37 \cdot 10^{5}$ & 21 & 6542.73 & 4.12 & 0.0612 \\
\hline Pure error & 7939.99 & 5 & 1588.00 & & \\
\hline Total & $8.13 \cdot 10^{5}$ & 53 & & & \\
\hline
\end{tabular}

Table 4. Analysis of variance (ANOVA) of the quadratic model adjusted to the extraction of total phenolic compounds.

\begin{tabular}{|c|c|c|c|c|c|}
\hline Factors & Sum of squares & Degrees of freedom & Mean square & $F$ value & $p$-value \\
\hline Model & $2.70 \cdot 10^{7}$ & 27 & $10.00 \cdot 10^{5}$ & 2.31 & 0.0181 \\
\hline $\mathrm{X}_{1}, \mathrm{MeOH}$ & $1.49 \cdot 10^{7}$ & 1 & $1.49 \cdot 10^{7}$ & 34.30 & 0.0000 \\
\hline $\mathrm{X}_{2}$, Temperature & 369552 & 1 & 369552 & 0.85 & 0.3641 \\
\hline $\mathrm{X}_{3}$, Amplitude & 127030 & 1 & 127030 & 0.29 & 0.5927 \\
\hline $\mathrm{X}_{4}$, Cycle & 70022.9 & 1 & 70022.9 & 0.16 & 0.6909 \\
\hline $\mathrm{X}_{5}, \mathrm{pH}$ & 9597.6 & 1 & 9597.6 & 0.02 & 0.8828 \\
\hline $\mathrm{X}_{6}$, Ratio & 844928 & 1 & 844928 & 1.95 & 0.1743 \\
\hline $\mathrm{X}_{1}^{2}$ & $1.12 \cdot 10^{6}$ & 1 & $1.12 \cdot 10^{6}$ & 2.59 & 0.1197 \\
\hline $\mathrm{X}_{1} \mathrm{X}_{2}$ & 95567.5 & 1 & 95567.5 & 0.22 & 0.6424 \\
\hline $\mathrm{X}_{1} \mathrm{X}_{3}$ & 12668.3 & 1 & 12668.3 & 0.03 & 0.8655 \\
\hline $\mathrm{X}_{1} \mathrm{X}_{4}$ & 401139 & 1 & 401139 & 0.93 & 0.3447 \\
\hline $\mathrm{X}_{1} \mathrm{X}_{5}$ & 19206.0 & 1 & 19206.0 & 0.04 & 0.8348 \\
\hline $\mathrm{X}_{1} \mathrm{X}_{6}$ & 432324 & 1 & 432324 & 1.00 & 0.3269 \\
\hline $\mathrm{X}_{2}^{2}$ & 783462 & 1 & 783462 & 1.81 & 0.1902 \\
\hline $\mathrm{X}_{2} \mathrm{X}_{3}$ & 202837 & 1 & 202837 & 0.47 & 0.4998 \\
\hline $\mathrm{X}_{2} \mathrm{X}_{4}$ & 49304.3 & 1 & 49304.3 & 0.11 & 0.7385 \\
\hline $\mathrm{X}_{2} \mathrm{X}_{5}$ & 18422.6 & 1 & 18422.6 & 0.04 & 0.8382 \\
\hline $\mathrm{X}_{2} \mathrm{X}_{6}$ & 312544 & 1 & 312544 & 0.72 & 0.4033 \\
\hline $\mathrm{X}_{3}^{2}$ & 171534 & 1 & 171534 & 0.40 & 0.5346 \\
\hline $\mathrm{X}_{3} \mathrm{X}_{4}$ & 848.51 & 1 & 848.51 & 0.00 & 0.9650 \\
\hline $\mathrm{X}_{3} \mathrm{X}_{5}$ & 11220.0 & 1 & 11220.0 & 0.03 & 0.8734 \\
\hline $\mathrm{X}_{3} \mathrm{X}_{6}$ & 10509.8 & 1 & 10509.8 & 0.02 & 0.8774 \\
\hline $\mathrm{X}_{4}^{2}$ & 725001 & 1 & 725001 & 1.67 & 0.2071 \\
\hline $\mathrm{X}_{4} \mathrm{X}_{5}$ & 253.8 & 1 & 253.8 & 0.00 & 0.9809 \\
\hline
\end{tabular}


Table 4. Continued...

\begin{tabular}{cccccc}
\hline Factors & Sum of squares & Degrees of freedom & Mean square & $F$ value & $p$-value \\
\hline $\mathrm{X}_{4} \mathrm{X}_{6}$ & 375502 & 1 & 375502 & 0.87 & 0.3603 \\
$\mathrm{X}_{5}{ }^{2}$ & 606211 & 1 & 606211 & 1.40 & 0.2475 \\
$\mathrm{X}_{5} \mathrm{X}_{6}$ & $1.04 \cdot 10^{6}$ & 1 & $1.04 \cdot 10^{6}$ & 2.40 & 0.1337 \\
$\mathrm{X}_{6}{ }^{2}$ & $1.00 \cdot 10^{6}$ & 1 & $1.00 \cdot 10^{6}$ & & \\
Residual & $1.13 \cdot 10^{7}$ & 26 & $4.33 \cdot 10^{5}$ & & \\
Lack of Fit & $1.12 \cdot 10^{7}$ & 21 & $5.34 \cdot 10^{5}$ & & \\
Pure Error & 39148.77 & 5 & 7829.75 & & \\
Total & $3.83 \cdot 10^{7}$ & 53 & & & \\
\hline
\end{tabular}

\subsection{Anthocyanins extraction method}

Once the 54 extractions had been carried out, the extracts were measured by UHPLC-UV-vis to quantify the anthocyanins (Table 2). The addition of individual anthocyanins was used to determine the total anthocyanins content. Thus, the real values for total anthocyanins were correlated with the predicted values obtained by Equation 2:

$$
\begin{aligned}
& Y_{T A}=447.97+5.24 X_{1}-37.68 X_{2}-4.60 X_{3}-16.04 X_{4}+1.12 X_{5} \\
& +17.85 X_{6}-164.22 X_{1}^{2}-24.66 X_{1} X_{2}+9.15 X_{1} X_{3}+2.623 X_{1} X_{4} \\
& +31.15 X_{1} X_{5}-17.42 X_{1} X_{6}-74.68 X_{2}^{2}+1.68 X_{2} X_{3}-2.55 X_{2} X_{4} \\
& +4.00 X_{2} X_{5}+7.50 X_{2} X_{6}-11.44 X_{3}^{2}-1.74 X_{3} X_{4}-17.27 X_{3} X_{5} \\
& +3.31 X_{3} X_{6}-68.71 X_{4}^{2}-8.87 X_{4} X_{5}+35.52 X_{4} X_{6}+38.21 X_{5}^{2} \\
& +3.27 X_{5} X_{6}+25.59 X_{6}^{2}
\end{aligned}
$$

A statistically significant agreement between experimental and estimated values for anthocyanins was achieved by using the second order polynomial equation. A coefficient of determination $\left(\mathrm{R}^{2}\right)$ of $82.1 \%$ was found. Therefore, the mathematical model can be applied to predict the amount of anthocyanins under specific experimental conditions. The regression of the obtained equation was evaluated from ANOVA (Table 3). The significance of the model terms was evaluated by $F$ test and $p$-value at $95 \%$ confidence level. According to the results (Table 3 ), the terms $\mathrm{X}_{2}, \mathrm{X}_{1}{ }^{2}, \mathrm{X}_{2}{ }^{2}$, and $\mathrm{X}_{4}{ }^{2}$ were considered significant. Lack of fit test showed a $p$-value higher than 0.05 (not significant) which means that the model fits well. To complete the information obtained, the $p$-values were also represented (Figure 2A) to evaluate the estimated effects of the linear, quadratic and interaction factors for the two second-order polynomial equation. As aforementioned, the most influential variables on the extraction of total anthocyanins in jabuticaba were $\mathrm{X}_{1}^{2}$ : quadratic interaction of solvent composition ( $p$-value: 0.0000$)$, $\mathrm{X}_{2}^{2}$ : quadratic interaction of temperature ( $p$-value: 0.0036$), \mathrm{X}_{2}$ : temperature ( $p$-value: 0.0204$)$, and $\mathrm{X}_{4}^{2}$ : quadratic effect of cycle ( $p$-value: 0.0067 ), as can be observed in the standardized Pareto chart obtained for total anthocyanins extraction (Figure 3A).

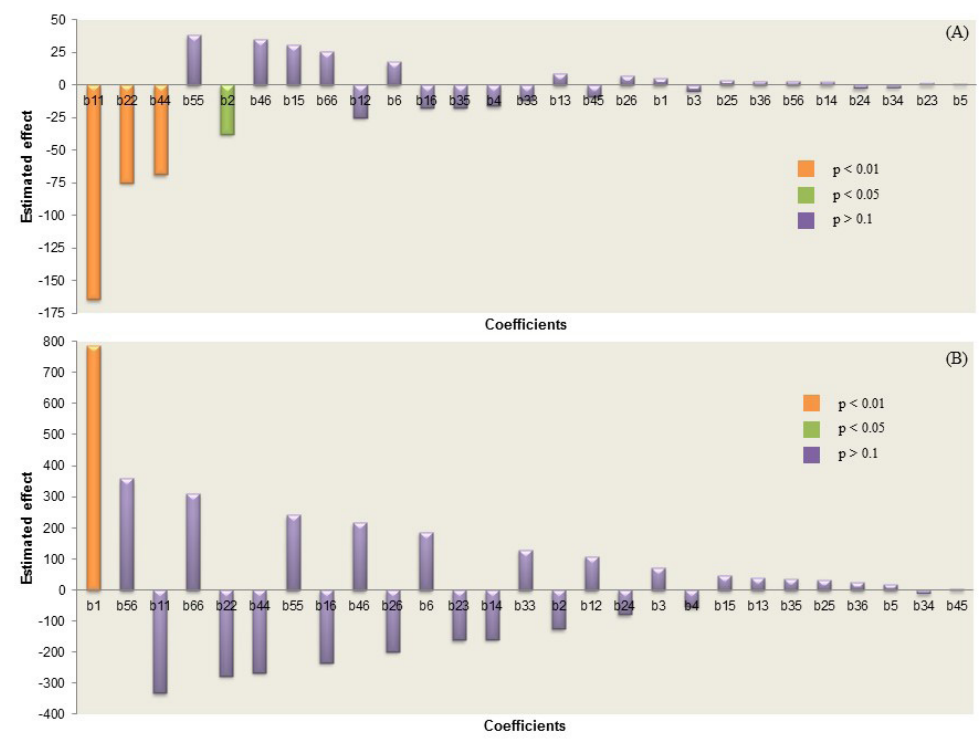

Figure 2. Estimated effects of the linear, quadratic and interaction factors for the two second-order polynomial equations. (A) Anthocyanins and (B) total phenolic compounds. 


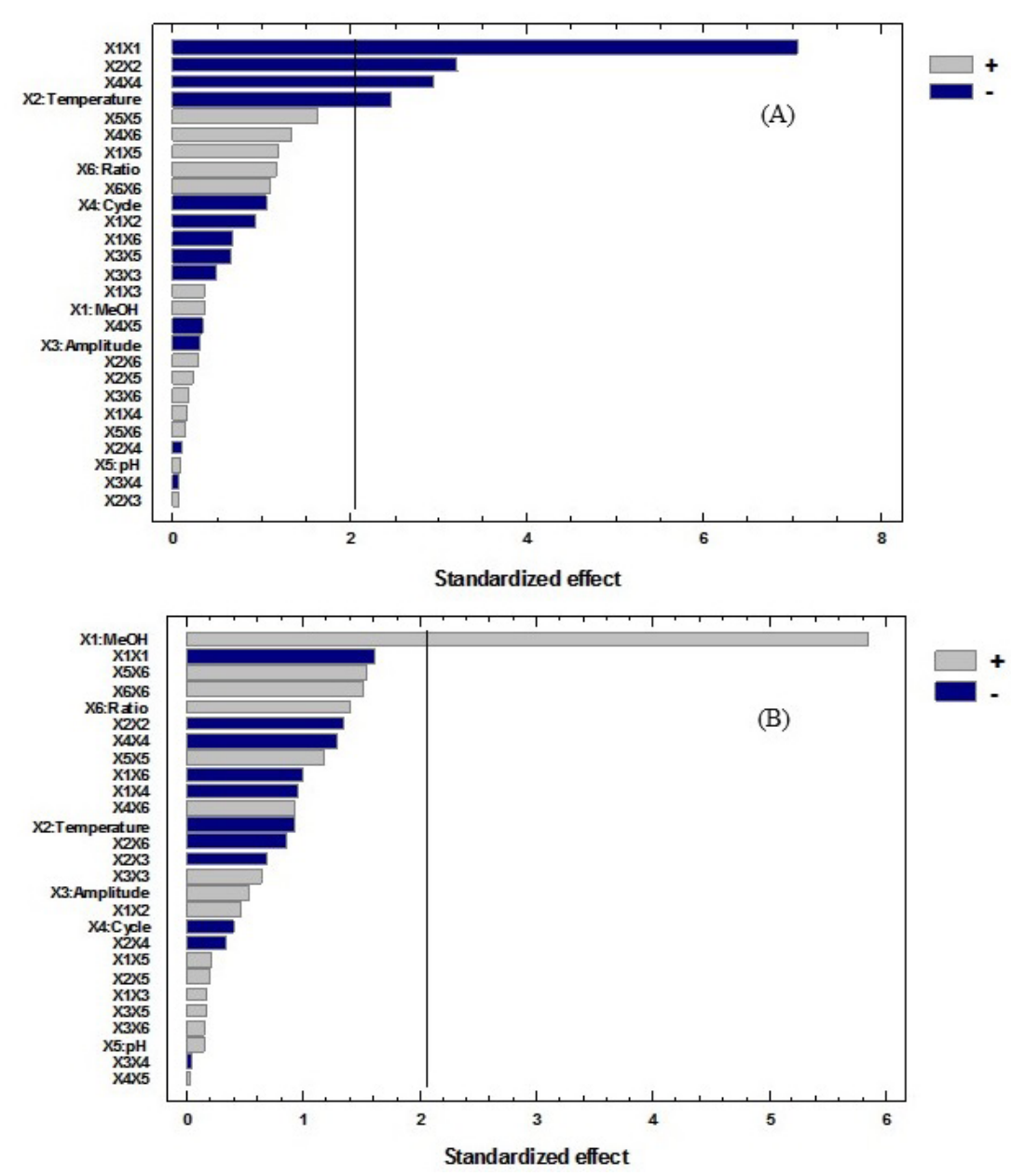

Figure 3. Standardized Pareto chart for (A) anthocyanins and (B) total phenolic compounds.

Significant interactions between effects were not observed ( $p$-value $>0.1$ ). It should be noted that the linear term of temperature had negative effects, which means that a decrease in its value led to a higher recovery of anthocyanins. It is known that anthocyanins are very sensitive to temperature, with the solubility of anthocyanins increasing in the solvent as temperature increases. However, these compounds are degraded when high temperatures are used (Fischer et al., 2013; He et al., 2016; Kechinski et al., 2010). Therefore, an optimum temperature of $39.8^{\circ} \mathrm{C}$ was selected for subsequent studies. Otherwise, the quadratic interaction of the percentage of methanol in the extracting solvent was one of the most influential variables in the extraction of anthocyanins due to the necessity to extract these bioactive compounds with solvents of similar polarity. Anthocyanins are polar molecules and, as a consequence, the characteristics of polar solvents favor the extraction and separation processes for these compounds (Strack \& Wray, 1988; Xavier et al., 2008). Many works found in literature have shown that hydroalcoholic (methanol or ethanol) mixtures are more efficient than pure solvents in the extraction of amphiphilic or moderately polar molecules, such as polyphenols (Espada-Bellido et al., 2017; Reátegui et al., 2014). This is due to the intermediate polarity of such mixtures, which is similar to those of phenolics (Machado et al., 2015). This similarity intensifies the molecular forces, thus increasing the solubility of the target compounds (Rezaie et al., 2015). Moreover, in mixtures, each solvent can play a specific role in the extraction: alcohol enhances the solubility of phenolics, whereas water helps desorption of the solute from the sample (Cai et al., 2016). Due to the analytical purpose of extraction in this work, methanol was more appropriate instead of ethanol due to its smaller size, lower viscosity, greater penetration power and lower cost (Blackhall et al., 2018).

The rest of the variables used in the design ( $\mathrm{pH}$, amplitude, cycle and solvent to sample ratio) were not significant ( $p$-value $>0.05)$ when extracting anthocyanins in jabuticaba using the UAE. With respect to the amplitude of ultrasound (applied power of ultrasound), there are authors who affirm that ultrasound can promote degradation of anthocyanins by the radical hydroxyl (OH.) and oxygen peroxide $\left(\mathrm{H}_{2} \mathrm{O}_{2}\right)$ produced inside the cavitation bubbles (Tiwari et al, 2010). There are numerous studies that show that the use of ultrasound cycles (pulse mode) improves the extraction of certain compounds of interest in certain matrices such as pomegranate peel (Kazemi et al., 2016), pistachio (Hashemi, Michiels, Asadi Yousefabad, \& Hosseini, 2015) or Boletus edulis (You et al., 2014), requiring less extraction time and lower energy consumption and solvents (Tiwari, 2015). With respect to $\mathrm{pH}$, anthocyanins are sensitive 
to this factor, which limit their use as food dyes and in the production of cosmetics and medical products. Although at $\mathrm{pH}$ values from 1.0 to 3.0 anthocyanins have a stable conformation, there are many works in literature with better extraction results at higher $\mathrm{pH}$ (3-7) (Machado et al., 2017). This is explained by the presence of organic acids in ultrasonic processes which may favor the degradation of anthocyanins through oxidation promoted by free radicals formed from these acids sonication (Tiwari et al., 2009). $\mathrm{pH}$ values higher than 7 have not been applied since anthocyanins can undergo irreversible degradation processes (Castañeda-Ovando et al., 2009). Finally, large solvent-to-sample ratio values usually improve the extraction rate, as a higher concentration gradient between the sample and the extraction solvent occurs (Barbero et al., 2008). Thus, the theoretical maximum (obtained by the design) for anthocyanin extraction should be obtained under the following optimum conditions: $51 \%$ methanol in water, $39.8^{\circ} \mathrm{C}, \mathrm{pH} 7.00,34 \%$ for ultrasound amplitude, 0.47 seconds for cycle, and 20:1.5 as the optimum solvent-to-sample ratio.

\subsection{Total phenolics extraction method}

As far as the total phenolic compounds are concerned, these bioactive compounds were measured in jabuticaba extracts by the Folin-Ciocalteu assay (Table 2). The real values for total phenolic compounds were correlated with the predicted values obtained by Equation 3:

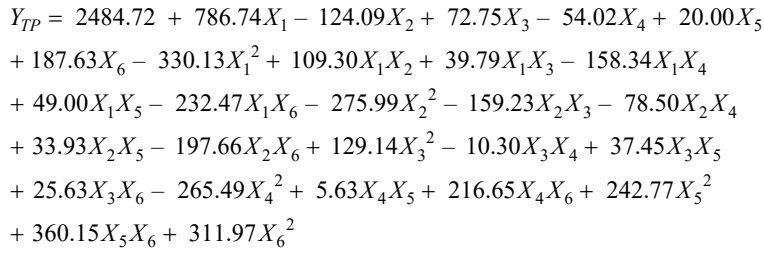

In this case, a low agreement between experimental and predicted values for phenolic compounds was obtained by using the second order polynomial equation. A coefficient of determination $\left(\mathrm{R}^{2}\right)$ of $70.6 \%$ was found. The regression of the obtained equation was also evaluated from ANOVA (Table 4). The significance of the model terms was evaluated by $F$ test and $p$-value at $95 \%$ confidence level. According to the results (Table 4), only the term $\mathrm{X}_{1}$ was considered significant. The lack of fit test showed a $p$-value $<0.0001$ which indicates evidence for a lack of fit, i.e., regression seems not adequate. However, this value of lack of fit is expected due to the nature of the phenolic compounds (Espada-Bellido et al., 2017, 2018). Phenolic compounds encompass molecules with a wide range of polarity and sizes, from simple phenolic compounds to tannins. This enormous variability makes that in this type of designs the lack of fit for phenolic compounds usually appears in this range. In any case, the optimal conditions obtained are a compromise situation to extract the most desirable quantity of these compounds.

From the $p$-values indicated in Figure $2 \mathrm{~B}$ and the standardized Pareto chart (Figure 3B) it can be concluded that the most influential variable for the extraction of phenolic compounds from jabuticaba fruits was $\mathrm{X}_{1}$ : the percentage of methanol used in the extraction solvent ( $p$-value: 0.0000$)$. Neither significant quadratic interactions nor significant interactions between factors were observed ( $p$-value $>0.1$ ). The increase in the percentage of methanol in the solvent mixture had a positive effect, indicating that an increase in this variable favored the recovery of phenolics in the jabuticaba extract. In this respect the optimum value was $72 \%$ methanol. Similar results for methanol percentages in the solvent composition in the range between $61 \%$ and $74.6 \%$ leading to increase extraction efficiency were reported in recent papers focused on the extraction of phenolic compounds from mulberries (Espada-Bellido et al., 2017, 2018). Thus, the best conditions for the maximum recovery of phenolics were: $72 \%$ methanol in water, $26^{\circ} \mathrm{C}, \mathrm{pH} 7.00,68.5 \%$ for ultrasound amplitude, 0.5 seconds for cycle, and 20:1.5 as the optimum solvent-to-sample ratio.

\subsection{Kinetic of the extraction process}

In order to study the optimum extraction time for total anthocyanins and total phenolic compounds, several extractions were run under the optimal extraction conditions. Extraction times between 2 and 30 minutes were evaluated in triplicate. The results for the recovery of both bioactive compounds are presented in Figure 4. It can be seen that the optimum extraction time to achieve the maximum recovery was 10 minutes. Longer times led to a decrease in the recovery which can be explained by the higher susceptibility of anthocyanins to degradation at high temperature (Cacace \& Mazza, 2003). The recovery seemed to level off after 20 minutes.

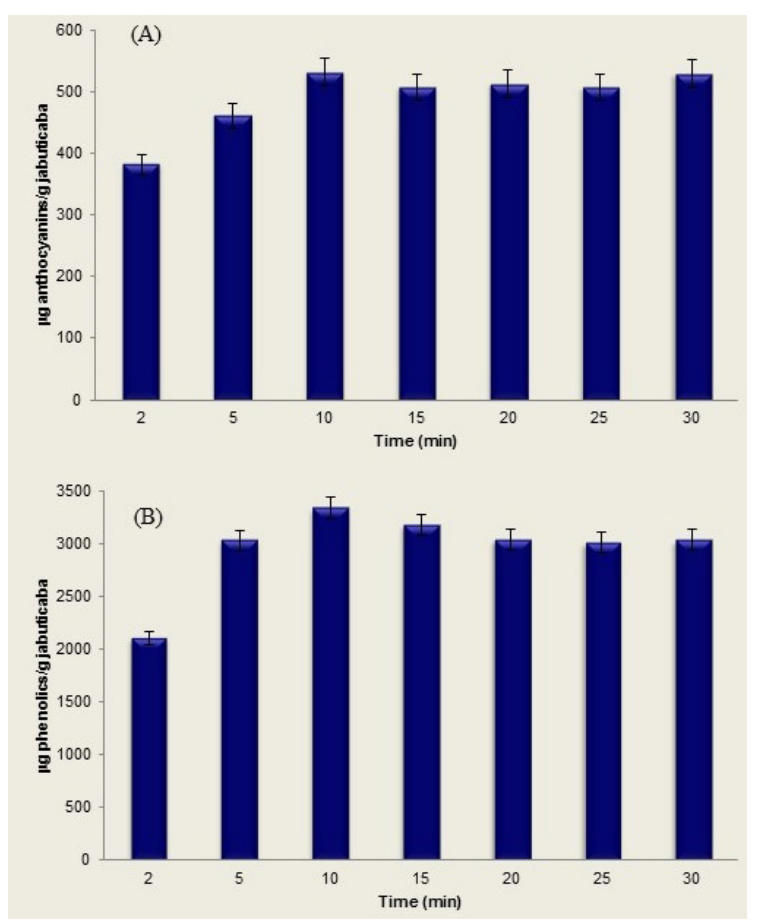

Figure 4. Extracted micrograms of (A) anthocyanins and (B) phenolics, per gram of jabuticaba fruit at different extraction times. 
Table 5. Total amount of anthocyanins $\left(\mu \mathrm{g} \mathrm{g}^{-1} \mathrm{FW}\right)$ and total phenolic compounds ( $\left.\mu \mathrm{g} \mathrm{g}^{-1} \mathrm{FW}\right)$ in jabuticaba fruit and its derived products $(n=3)$.

\begin{tabular}{lcc}
\hline \multirow{2}{*}{ Jabuticaba sample } & Total anthocyanins & Total phenolic compounds \\
\cline { 2 - 3 } & $\left(\mu \mathrm{g} \mathrm{g}^{-1}\right)$ & $\left(\mu \mathrm{g} \mathrm{g}^{-1}\right)$ \\
\hline Fruit (A) & $538 \pm 25$ & $3342 \pm 120$ \\
Fruit (B) & $503 \pm 23$ & $3216 \pm 116$ \\
Jam (A) & $81 \pm 4$ & $1273 \pm 46$ \\
Jam (B) & $85 \pm 4$ & $1335 \pm 48$ \\
\hline
\end{tabular}

\subsection{Precision of the methods}

The precision was assessed by the repeatability (within the same day) and intermediate precision (between different days) expressed as the coefficient of variance (CV). A total of 30 extractions were performed under optimal conditions on three consecutive days, distributed as follows: 12 extractions performed on the first day of the study for repeatability, and 9 more extractions on each of the next two consecutive days for intermediate precision.

Good repeatability (CV 4.31\% and 3.17\%) and intermediate precision (CV $4.68 \%$ and $3.60 \%$ ) were observed for anthocyanins and total phenolic compounds, respectively, with both values within the acceptable limits for precision $(<5 \%)$.

\subsection{Application to jabuticaba fruit and its derived products}

Once the new extraction methods had been developed, a further study was carried out to quantify the anthocyanins and total phenolic compounds in several jabuticaba samples: two jabuticaba fruits (without seeds) and two derived products such as jabuticaba jams. Extractions were carried out in triplicate. The results are presented in Table 5. The observed results correspond to the reported concentrations found in literature of anthocyanins and phenolics in jabuticaba (Alezandro et al., 2013; Wu et al., 2013). It is worth highlighting the elevated concentrations of phenolic compounds in jabuticaba fruit (more than $3000 \mu \mathrm{g} \mathrm{g}^{-1}$ ) compared with other fruits described in the recent literature as excellent sources of phenolics, such as grapes $\left(826.27 \mu \mathrm{g} \mathrm{g}^{-1}\right)$ (Aadil et al., 2013), orange peel (2758 $\left.\mu \mathrm{g} \mathrm{g}^{-1}\right)$ (Khan et al., 2010), and mulberry (1301 $\mathrm{\mu g} \mathrm{g}^{-1}$ ) (Espada-Bellido et al., 2017). Comparison of the fruit and the jam samples shows that jabuticaba fruit contained higher contents of total phenolic compounds than jabuticaba jams. This difference can be attributed to the elaboration and treatment of the samples. Jams rarely have a percentage greater than $40 \%$ of fruit content, with the rest of the sample consisting of sugars and other additives. Moreover, the degradation of a proportion of the anthocyanins during the treatment of the jams, mainly due to the high temperatures, and during storage and transportation can also be considered as a significant reason for the differences observed (Sui et al., 2016). Regarding anthocyanins, although jabuticaba also has higher anthocyanins contents compared to other similar fruits studied previously, lower values could also be observed in jabuticaba samples compared to total phenolics. The low anthocyanin contents could be attributed to the manufacturing process or storage of the products, which can suffer severe degradation of anthocyanins as they are very sensitive to temperature and other conditions (Fracassetti et al., 2013; Hellström et al., 2013).

\section{Conclusions}

The study reported here shows the optimization of ultrasoundassisted extraction (UAE) methods for both total anthocyanins and total phenolic compounds from jabuticaba fruit. It was found that solvent composition (\% methanol) was the most influential variable in both cases. Other relevant variables for anthocyanins were temperature and cycle of extraction. An optimum extraction time of 10 minutes was sufficient to achieve quantitative extraction of the bioactive compounds. Both methods showed good precision. The new methods were successfully applied to jabuticaba samples (fruit and jam). This is the first time UAE has been optimized for analytical purposes for the determination of bioactive compounds in this fruit, which has characteristically high contents of anthocyanins and other phenolic compounds.

\section{References}

Aadil, R. M., Zeng, X. A., Han, Z., \& Sun, D. W. (2013). Effects of ultrasound treatments on quality of grapefruit juice. Food Chemistry, 141(3), 3201-3206. http://dx.doi.org/10.1016/j.foodchem.2013.06.008. PMid:23871078.

Abe, L. T., Lajolo, F. M., \& Genovese, M. I. (2012). Potential dietary sources of ellagic acid and other antioxidants among fruits consumed in Brazil: Jabuticaba (Myrciaria jaboticaba (Vell.) Berg). Journal of the Science of Food and Agriculture, 92(8), 1679-1687. http://dx.doi. org/10.1002/jsfa.5531. PMid:22173652.

Alezandro, M. R., Dubé, P., Desjardins, Y., Lajolo, F. M., \& Genovese, M. I. (2013). Comparative study of chemical and phenolic compositions of two species of jaboticaba: Myrciaria jaboticaba (Vell.) Berg and Myrciaria cauliflora (Mart.) O. Berg. Food Research International, 54(1), 468-477. http://dx.doi.org/10.1016/j.foodres.2013.07.018.

Alves, A. P. C., Corrêa, A. D., Pinheiro, A. C. M., \& Oliveira, F. C. (2013). Flour and anthocyanin extracts of jaboticaba skins used as a natural dye in yogurt. International Journal of Food Science \& Technology, 48(10), 2007-2013.

Alves, A. P. C., Marques, T. R., Carvalho, T. C. L., Pinheiro, A. C. M., Ramos, E. M., \& Corrêa, A. D. (2016). Elaboration and acceptability of restructured hams added with jabuticaba skin. Food Science and Technology, 37(2), 232-238. http://dx.doi.org/10.1590/1678-457x.19016.

Barbero, G. F., Liazid, A., Palma, M., \& Barroso, C. G. (2008). Ultrasoundassisted extraction of capsaicinoids from peppers. Talanta, 75(5), 1332-1337. http://dx.doi.org/10.1016/j.talanta.2008.01.046. PMid:18585221.

Barizão, É. O., Boeing, J. S., Martins, A. C., Visentainer, J. V., \& Almeida, V. C. (2015). Application of Response Surface Methodology for the Optimization of Ultrasound-Assisted Extraction of Pomegranate (Punica granatum L. ) Seed Oil. Food Analytical Methods, 8(9), 2392-2400. http://dx.doi.org/10.1007/s12161-015-0135-5.

Baş, D., \& Boyacı, İ. H. (2007). Modeling and optimization I: Usability of response surface methodology. Journal of Food Engineering, 78(3), 836-845. http://dx.doi.org/10.1016/j.jfoodeng.2005.11.024.

Batista, Â. G., Lenquiste, S. A., Cazarin, C. B. B., Silva, J. K., Luiz-Ferreira, A., Bogusz, S. Jr, Hantao, L. W., Souza, R. N., Augusto, F., Prado, M. A., \& Maróstica, M. R. Jr (2014). Intake of jaboticaba peel attenuates oxidative stress in tissues and reduces circulating saturated lipids of rats with high-fat diet-induced obesity. Journal of Functional Foods, 6(1), 450-461. http://dx.doi.org/10.1016/j.jff.2013.11.011. 
Blackhall, M. L., Berry, R., Davies, N. W., \& Walls, J. T. (2018). Optimized extraction of anthocyanins from Reid Fruits' Prunus avium "Lapins" cherries. Food Chemistry, 256, 280-285. http://dx.doi.org/10.1016/j. foodchem.2018.02.137. PMid:29606449.

Borges, L. L., Conceição, E. C., \& Silveira, D. (2014). Active compounds and medicinal properties of Myrciaria genus. Food Chemistry, 153, 224-233. http://dx.doi.org/10.1016/j.foodchem.2013.12.064. PMid:24491724.

Cacace, J. E., \& Mazza, G. (2003). Optimization of Extraction of Anthocyanins from Black Currants with Aqueous Ethanol. Journal of Food Science, 68(1), 240-248. http://dx.doi.org/10.1111/j.1365-2621.2003.tb14146.x.

Cai, Z., Qu, Z., Lan, Y., Zhao, S., Ma, X., Wan, Q., Jing, P., \& Li, P. (2016). Conventional, ultrasound-assisted, and accelerated-solvent extractions of anthocyanins from purple sweet potatoes. Food Chemistry, 197(Pt A), 266-272. http://dx.doi.org/10.1016/j.foodchem.2015.10.110. PMid:26616949.

Castañeda-Ovando, A., Pacheco-Hernández, M. de L., Páez-Hernández, M. E., Rodríguez, J. A., \& Galán-Vidal, C. A. (2009). Chemical studies of anthocyanins: A review. Food Chemistry, 113(4), 859-871. http:// dx.doi.org/10.1016/j.foodchem.2008.09.001.

Costa, R. C., Cunha, L. C. Jr., Morgenstern, T. B., Teixeira, G. H. A., \& Lima, K. M. G. (2016). Classification of jaboticaba fruits at three maturity stages using NIRS and LDA. Analytical Methods, 8(11), 2533-2538. http://dx.doi.org/10.1039/C5AY03212A.

Dessimoni-Pinto, N. A. V., Moreira, W. A., Cardoso, L. M., \& Pantoja, L. A. (2011). Jaboticaba peel for jelly preparation: an alternative technology. Food Science and Technology, 31(4), 864-869. http:// dx.doi.org/10.1590/S0101-20612011000400006.

Díaz-de-Cerio, E., Tylewicz, U., Verardo, V., Fernández-Gutiérrez, A., Segura-Carretero, A., \& Romani, S. (2017). Design of sonotrode ultrasound-assisted extraction of phenolic compounds from Psidium guajava L. Leaves. Food Analytical Methods, 10(8), 2781-2791. http:// dx.doi.org/10.1007/s12161-017-0836-Z.

Ding, Y., Zheng, J., Xia, X., Ren, T., \& Kan, J. (2016). Box-Behnken design for the optimization of nanoscale retrograded starch formation by high-power ultrasonication. Lebensmittel-Wissenschaft + Technologie, 67, 206-213. http://dx.doi.org/10.1016/j.lwt.2015.11.022.

Dranca, F., \& Oroian, M. (2016). Optimization of ultrasound-assisted extraction of total monomeric anthocyanin (TMA) and total phenolic content (TPC) from eggplant (Solanum melongena L.) peel. Ultrasonics Sonochemistry, 31, 637-646. http://dx.doi.org/10.1016/j. ultsonch.2015.11.008. PMid:26701808.

Espada-Bellido, E., Ferreiro-González, M., Barbero, G. F., Carrera, C., Palma, M., \& Barroso, C. G. (2018). Alternative extraction method of bioactive compounds from mulberry Morus nigra L. pulp using pressurized-liquid extraction. Food Analytical Methods, 11(9), 23842395. http://dx.doi.org/10.1007/s12161-018-1218-x.

Espada-Bellido, E., Ferreiro-González, M., Carrera, C., Palma, M., Barroso, C. G., \& Barbero, G. F. (2017). Optimization of the ultrasoundassisted extraction of anthocyanins and total phenolic compounds in mulberry (Morus nigra) pulp. Food Chemistry, 219, 23-32. http:// dx.doi.org/10.1016/j.foodchem.2016.09.122. PMid:27765221.

Filip, S., Pavlić, B., Vidović, S., Vladić, J., \& Zeković, Z. (2017). Optimization of microwave-assisted extraction of polyphenolic compounds from ocimum basilicum by response surface methodology. Food Analytical Methods, 10(7), 2270-2280. http://dx.doi.org/10.1007/ s12161-017-0792-7.

Fischer, U. A., Carle, R., \& Kammerer, D. R. (2013). Thermal stability of anthocyanins and colourless phenolics in pomegranate (Punica granatum L.) juices and model solutions. Food Chemistry, 138(2-3),
1800-1809. http://dx.doi.org/10.1016/j.foodchem.2012.10.072. PMid:23411312.

Fracassetti, D., Del Bo, C., Simonetti, P., Gardana, C., Klimis-Zacas, D., \& Ciappellano, S. (2013). Effect of time and storage temperature on anthocyanin decay and antioxidant activity in wild blueberry (Vaccinium angustifolium) powder. Journal of Agricultural and Food Chemistry, 61(12), 2999-3005. http://dx.doi.org/10.1021/jf3048884. PMid:23489164.

Franquin-Trinquier, S., Maury, C., Baron, A., Le Meurlay, D., \& Mehinagic, E. (2014). Optimization of the extraction of apple monomeric phenolics based on response surface methodology: Comparison of pressurized liquid-solid extraction and manual-liquid extraction. Journal of Food Composition and Analysis, 34(1), 56-67. http://dx.doi. org/10.1016/j.jfca.2014.01.005.

Grosso, C., Ferreres, F., Gil-Izquierdo, A., Valentão, P., Sampaio, M., Lima, J., \& Andrade, P. B. (2014). Box-Behnken factorial design to obtain a phenolic-rich extract from the aerial parts of Chelidonium majus L. Talanta, 130, 128-136. http://dx.doi.org/10.1016/j. talanta.2014.06.043. PMid:25159389.

Hashemi, S. M. B., Michiels, J., Asadi Yousefabad, S. H., \& Hosseini, M. (2015). Kolkhoung (Pistacia khinjuk) kernel oil quality is affected by different parameters in pulsed ultrasound-assisted solvent extraction. Industrial Crops and Products, 70, 28-33. http://dx.doi. org/10.1016/j.indcrop.2015.03.023.

He, B., Zhang, L.-L., Yue, X.-Y., Liang, J., Jiang, J., Gao, X.-L., \& Yue, P.-X. (2016). Optimization of Ultrasound-Assisted Extraction of phenolic compounds and anthocyanins from blueberry (Vaccinium ashei) wine pomace. Food Chemistry, 204, 70-76. http://dx.doi. org/10.1016/j.foodchem.2016.02.094. PMid:26988477.

Hellström, J., Mattila, P., \& Karjalainen, R. (2013). Stability of anthocyanins in berry juices stored at different temperatures. Journal of Food Composition and Analysis, 31(1), 12-19. http://dx.doi.org/10.1016/j. jfca.2013.02.010.

Kazemi, M., Karim, R., Mirhosseini, H., \& Hamid, A. A. (2016). Optimization of pulsed ultrasound-assisted technique for extraction of phenolics from pomegranate peel of Malas variety: Punicalagin and hydroxybenzoic acids. Food Chemistry, 206, 156-166. http:// dx.doi.org/10.1016/j.foodchem.2016.03.017. PMid:27041311.

Kechinski, C. P., Guimarães, P. V. R., Noreña, C. P. Z., Tessaro, I. C., \& Marczak, L. D. F. (2010). Degradation kinetics of anthocyanin in blueberry juice during thermal treatment. Journal of Food Science, 75(2), 173-176. http://dx.doi.org/10.1111/j.1750-3841.2009.01479.x. PMid:20492222.

Khan, M. K., Abert-Vian, M., Fabiano-Tixier, A. S., Dangles, O., \& Chemat, F. (2010). Ultrasound-assisted extraction of polyphenols (flavanone glycosides) from orange (Citrus sinensis L.) peel. Food Chemistry, 119(2), 851-858. http://dx.doi.org/10.1016/j.foodchem.2009.08.046.

Lazar, L., Talmaciu, A. I., Volf, I., \& Popa, V. I. (2016). Kinetic modeling of the ultrasound-assisted extraction of polyphenols from Picea abies bark. Ultrasonics Sonochemistry, 32, 191-197. http://dx.doi. org/10.1016/j.ultsonch.2016.03.009. PMid:27150760.

Lenquiste, S. A., Marineli, R. S., Moraes, É. A., Dionísio, A. P., Brito, E. S., \& Maróstica, M. R. (2015). Jaboticaba peel and jaboticaba peel aqueous extract shows in vitro and in vivo antioxidant properties in obesity model. Food Research International, 77, 162-170. http:// dx.doi.org/10.1016/j.foodres.2015.07.023.

Liazid, A., Schwarz, M., Varela, R. M., Palma, M., Guillén, D. A., Brigui, J., Macías, F. A., \& Barroso, C. G. (2010). Evaluation of various extraction techniques for obtaining bioactive extracts from pine seeds. Food and Bioproducts Processing, 88(2-3), 247-252. http:// dx.doi.org/10.1016/j.fbp.2009.11.004. 
Machado, A. P. D. F., Pasquel-Reátegui, J. L., Barbero, G. F., \& Martínez, J. (2015). Pressurized liquid extraction of bioactive compounds from blackberry (Rubus fruticosus L.) residues: A comparison with conventional methods. Food Research International, 77, 675-683. http://dx.doi.org/10.1016/j.foodres.2014.12.042.

Machado, A. P. D. F., Pereira, A. L. D., Barbero, G. F., \& Martínez, J. (2017). Recovery of anthocyanins from residues of Rubus fruticosus, Vaccinium myrtillus and Eugenia brasiliensis by ultrasound assisted extraction, pressurized liquid extraction and their combination. Food Chemistry, 231, 1-10. http://dx.doi.org/10.1016/j.foodchem.2017.03.060. PMid:28449984.

Magnussonm, B., \& Örnemark, U. (2014). The fitness for purpose of analytical methods - a laboratory guide to method validation and related topics (2nd ed.). Torino Italy: Eurachem Guide. http://doi. org/978-91-87461-59-0.

Mitra, S. K. (2010). Important Myrtaceae fruit crops. Acta Horticulturae, (849), 33-38. http://dx.doi.org/10.17660/ActaHortic.2010.849.2.

Nascimento, T. P., Bettiol, J. E. No., Pereira, R. A., Castro, I. A., Chagas, E. A., Lajolo, F. M., \& Cordenunsi, B. R. (2013). Effect of thinning on flower and fruit and of edible coatings on postharvest quality of jaboticaba fruit stored at low temperature. Food Science and Technology, 33(3), 424-433. http://dx.doi.org/10.1590/S010120612013005000071.

Paula, J. A. M., Brito, L. F., Caetano, K. L. F. N., Rodrigues, M. C. M., Borges, L. L., \& Conceição, E. C. (2016). Ultrasound-assisted extraction of azadirachtin from dried entire fruits of Azadirachta indica A. Juss. (Meliaceae) and its determination by a validated HPLC-PDA method. Talanta, 149, 77-84. http://dx.doi.org/10.1016/j. talanta.2015.11.005. PMid:26717816.

Reátegui, J. L. P., Machado, A. P. F., Barbero, G. F., Rezende, C. A., \& Martínez, J. (2014). Extraction of antioxidant compounds from blackberry (Rubus sp.) bagasse using supercritical CO2 assisted by ultrasound. The Journal of Supercritical Fluids, 94, 223-233. http:// dx.doi.org/10.1016/j.supflu.2014.07.019.

Reynertson, K. A., Wallace, A. M., Adachi, S., Gil, R. R., Yang, H., Basile, M. J., D’Armiento, J., Weinstein, I. B., \& Kennelly, E. J. (2006). Bioactive depsides and anthocyanins from jaboticaba (Myrciaria cauliflora). Journal of Natural Products, 69(8), 1228-1230. http:// dx.doi.org/10.1021/np0600999. PMid:16933884.

Rezaie, M., Farhoosh, R., Iranshahi, M., Sharif, A., \& Golmohamadzadeh, S. (2015). Ultrasonic-assisted extraction of antioxidative compounds from Bene (Pistacia atlantica subsp. mutica) hull using various solvents of different physicochemical properties. Food Chemistry, 173, 577-583. http://dx.doi.org/10.1016/j.foodchem.2014.10.081. PMid:25466062.

Rodrigues, S., Fernandes, F. A. N., Brito, E. S., Sousa, A. D., \& Narain, N. (2015). Ultrasound extraction of phenolics and anthocyanins from jabuticaba peel. Industrial Crops and Products, 69, 400-407. http://dx.doi.org/10.1016/j.indcrop.2015.02.059.

Sá, L. Z. C. M., Castro, P. F. S., Lino, F. M. A., Bernardes, M. J. C., Viegas, J. C. J., Dinis, T. C. P., Santana, M. J., Romao, W., Vaz, B. G., Lião, L. M., Ghedini, P. C., Rocha, M. L., \& Gil, E. S. (2014). Antioxidant potential and vasodilatory activity of fermented beverages of jabuticaba berry (Myrciaria jaboticaba). Journal of Functional Foods, 8(1), 169-179. http://dx.doi.org/10.1016/j.jff.2014.03.009.

Santos, D. T., Veggi, P. C., \& Meireles, M. A. A. (2010). Extraction of antioxidant compounds from Jabuticaba (Myrciaria cauliflora) skins: Yield, composition and economical evaluation. Journal of Food Engineering, 101(1), 23-31. http://dx.doi.org/10.1016/j. jfoodeng.2010.06.005.

Sharmila, G., Nikitha, V. S., Ilaiyarasi, S., Dhivya, K., Rajasekar, V., Kumar, N. M., Muthukumaran, C., \& Muthukumaran, C. (2016). Ultrasound assisted extraction of total phenolics from Cassia auriculata leaves and evaluation of its antioxidant activities. Industrial Crops and Products, 84, 13-21. http://dx.doi.org/10.1016/j.indcrop.2016.01.010.

Silva, P. H. A., Faria, F. C., Tonon, B., Mota, S. J. D., \& Pinto, V. T. (2008). Avaliação da composição química de fermentados alcoólicos de jabuticaba (Myrciaria jabuticaba). Quimica Nova, 31(3), 595-600. http://dx.doi.org/10.1590/S0100-40422008000300025.

Singleton, V. L., \& Rossi, J. A. (1965). Colorimetry of total phenolics with phosphomolybdic-phosphotungstic acid reagents. American Journal of Enology and Viticulture, 16, 144-158.

Singleton, V. L., Orthofer, R., \& Lamuela-Raventós, R. M. (1999). Analysis of total phenols and other oxidation substrates and antioxidants by means of Folin-Ciocalteu reagent. In P. Lester (Ed.), Methods in enzymology (pp. 152-178). Cambridge: Academic Press.

Strack, D., \& Wray, V. (1988). The anthocyanins. In J. B. Harborne (Ed.), The flavonoids (pp. 1-20). London: Chapman \& Hall Ltd.

Sui, X., Bary, S., \& Zhou, W. (2016). Changes in the color, chemical stability and antioxidant capacity of thermally treated anthocyanin aqueous solution over storage. Food Chemistry, 192, 516-524. http:// dx.doi.org/10.1016/j.foodchem.2015.07.021. PMid:26304379.

Teixeira, G. H. A., Durigan, M. F. B., \& Durigan, J. F. (2011). Jaboticaba (Myrciaria cauliflora (Mart.) O.Berg. [Myrtaceae]). In Postharvest biology and technology of tropical and subtropical fruits (chapt. 11, pp. 246-274). Cambridge: Woodhead Publishing.

Tiwari, B. K. (2015). Ultrasound: a clean, green extraction technology. Trends in Analytical Chemistry, 71, 100-109. http://dx.doi.org/10.1016/j. trac.2015.04.013.

Tiwari, B. K., O’Donnell, C. P., \& Cullen, P. J. (2009). Effect of non thermal processing technologies on the anthocyanin content of fruit juices. Trends in Food Science \& Technology, 20(3-4), 137-145. http://dx.doi.org/10.1016/j.tifs.2009.01.058.

Tiwari, B. K., Patras, A., Brunton, N., Cullen, P. J., \& O’Donnell, C. P. (2010). Effect of ultrasound processing on anthocyanins and color of red grape juice. Ultrasonics Sonochemistry, 17(3), 598-604. http:// dx.doi.org/10.1016/j.ultsonch.2009.10.009. PMid:20015673.

Wang, L., \& Weller, C. L. (2006). Recent advances in extraction of nutraceuticals from plants. Trends in Food Science \& Technology, 17(6), 300-312. http://dx.doi.org/10.1016/j.tifs.2005.12.004.

Wu, S.-B., Long, C., \& Kennelly, E. J. (2013). Phytochemistry and health benefits of jaboticaba, an emerging fruit crop from Brazil. Food Research International, 54(1), 148-159. http://dx.doi.org/10.1016/j. foodres.2013.06.021.

Xavier, M. F., Lopes, T. J., Quadri, M. G. N., \& Quadri, M. B. (2008). Extraction of Red Cabbage Anthocyanins: Optimization of the Operation Conditions of the Column Process. Brazilian Archives of Biology and Technology, 51(1), 143-152. http://dx.doi.org/10.1590/ S1516-89132008000100018.

You, Q., Yin, X., \& Ji, C. (2014). Pulsed counter-current ultrasoundassisted extraction and characterization of polysaccharides from Boletus edulis. Carbohydrate Polymers, 101(1), 379-385. http:// dx.doi.org/10.1016/j.carbpol.2013.09.031. PMid:24299786. 